\title{
Risk factor analysis of insufficient fluid intake among urban adults in Wuxi, China: a classification and regression tree analysis
}

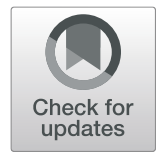

\author{
Hao Zheng ${ }^{1}$, Juan Fei ${ }^{1}$, Lan Zhang ${ }^{2}$, Weijie Zhou ${ }^{3}$, Zhen Ding ${ }^{1 *}$ and Wenbiao Hu${ }^{4^{*}}$
}

\begin{abstract}
Background: Dehydration due to insufficient fluid intake (IFI) is detrimental to health. This cross-sectional study aimed to assess the fluid intake of urban adults in Wuxi, China, and to identify potential risk factors contributing to IFI.

Methods: Adults were selected from the urban area of Wuxi, China, using a multiple-stage random sampling method. The fluid intake information was obtained with a 24-h self-reported diary over seven consecutive days in both summer and winter of 2015. A classification and regression tree (CART) analysis was conducted to detect the potential risk factors associated with IFI. CART is a machine-learning algorithm that portions the data into subsets by threshold.

Results: A total of 584 adults aged 18-87 years were included. The results showed that the median (P25-P75) values of daily fluid intake of the participants were 1100 (800-1550) $\mathrm{mL}$ in summer and 1000 (750-1300) $\mathrm{mL}$ in winter. Women had a higher prevalence of IFI than men in both summer (odds ratio $(\mathrm{OR})=2.683,95 \%$ confidence interval (Cl): 1.830-3.934) and winter $(\mathrm{OR}=2.636,95 \% \mathrm{Cl}: 1.677-4.142)$. The results of CART analysis showed that, in summer, BMI $<25 \mathrm{~kg} / \mathrm{m}^{2}$ (probability: 64.2\%) and age $<64$ years (probability: 67.4\%) were main risk factors of IFI for men, and $\mathrm{BMl}<29 \mathrm{~kg} / \mathrm{m}^{2}$ (probability: $81.6 \%$ ) and living in C Community (probability: $86.7 \%$ ) were main risk factors for women. In winter, age $<40$ years (probability: $81.8 \%$ ) and $\mathrm{BMI}<20 \mathrm{~kg} / \mathrm{m}^{2}$ (probability: $94.5 \%$ ) were identified as main risk factors of IFI for men and women, respectively.

Conclusions: Most of the participants living in the study site had IFI. The fluid consumption varied by gender, age, location, and BMI. The findings could be useful for the implementation and optimization of intervention programs by identifying the individuals who may at greater risk of dehydration.
\end{abstract}

Keywords: Fluid intake, Risk factors, Adults, CART

\section{Background}

Water is an essential constituent of the human body. It acts not only as a medium involved in reaction processes

\footnotetext{
*Correspondence: jscdc@126.com; w2.hu@qut.edu.au

'Department of Environmental Health, Jiangsu Provincial Center for Disease Control and Prevention, No. 172 Jiangsu Road, Nanjing 210009, China

${ }^{4}$ School of Public Health and Social Work, Institute of Health and Biomedical Innovation, Queensland University of Technology, Brisbane, Queensland 4059, Australia

Full list of author information is available at the end of the article
}

but also as a carrier transporting nutrients and wastes in and out of cells $[1,2]$. Adequate fluid intake plays an important role in maintaining water balance, and dehydration may occur when the water balance is broken. It has been reported that dehydration is associated with urological, gastrointestinal, circulatory, and neurological disorders [3-6]. Even mild dehydration has an adverse impact on cognitive and performance functions, and elderly people are vulnerable to water deficit $[6,7]$.

\section{$\mathrm{BMC}$}

(c) The Author(s). 2020 Open Access This article is licensed under a Creative Commons Attribution 4.0 International License, which permits use, sharing, adaptation, distribution and reproduction in any medium or format, as long as you give appropriate credit to the original author(s) and the source, provide a link to the Creative Commons licence, and indicate if changes were made. The images or other third party material in this article are included in the article's Creative Commons licence, unless indicated otherwise in a credit line to the material. If material is not included in the article's Creative Commons licence and your intended use is not permitted by statutory regulation or exceeds the permitted use, you will need to obtain permission directly from the copyright holder. To view a copy of this licence, visit http://creativecommons.org/licenses/by/4.0/ The Creative Commons Public Domain Dedication waiver (http://creativecommons.org/publicdomain/zero/1.0/) applies to the data made available in this article, unless otherwise stated in a credit line to the data. 
Since the human body itself cannot produce enough water to sustain life, we mainly ingest water from plain water, beverages, and food moisture [8]. Fluid consumption requirements vary between individuals and are influenced by many factors, such as physical activity levels, environmental conditions, and physiological status [8]. The recommended daily adequate intake for total water intake set by the Food and Nutrition Board of the Institute of Medicine in the United States is $3.7 \mathrm{~L}$ and $2.7 \mathrm{~L}$ for young men and women, respectively [9]. The European Food Safety Authority set the threshold of adequate total water intake at $2.5 \mathrm{~L} /$ day for men and $2 \mathrm{~L} /$ day for women [10]. The World Health Organization recommends a fluid intake of $1.5 \mathrm{~L} /$ day [11]. In 2016, the Chinese Nutrition Society (CNS) recommended a daily adequate intake for adults ranging from 1.5 to $1.7 \mathrm{~L}$ [12]. Previous research in four Chinese cities showed that male adults had a higher fluid intake than females and significant differences were found for fluid intake among the four cities [13]. Similarly, a recent national survey performed by Zhang et al.in 27 cities in China, suggested that the fluid intake was significantly higher in male vs female, and a significant difference was found for fluid intake between cities with different socioeconomic status [14]. Some studies indicated that the water intake was significantly higher in boys than in girls among primary and middle school students $[15,16]$, and was higher in urban than in rural regions $[17$, 18]. In addition, a few studies suggested that drinking behaviors (different consumption periods and times) had a close association with water consumption $[16,19,20]$. Zhang et al. identified 24-h urine volume and osmolality as possible key predictors for hydration status among male college students [21]. Wang et al. reported that obese adolescents drank more water than normal weight and overweight counterparts in Shanghai, China [22]. Moreover, it has been reported that the amount of water intake was affected by season, gender, and body mass index (BMI) in China [23-25]. These findings suggest that the fluid intake may differ by region and that potential risk factors contributing to IFI need to be further explored.

Understanding the interaction of determinants of IFI can facilitate the planning and implementation of prevention or intervention programs. However, most previous studies used only univariate or multivariate models, which did not assess the interaction across variables [13, 14, 26-28]. The classification and regression tree (CART) analysis is a very useful method that can potentially better accommodate these complex interactions since they avoid some of the assumptions associated with linear regression [29]. In the present study, we aimed to assess the situation of fluid intake among adults in the urban area of Wuxi, China and to identify potential risk factors contributing to IFI using CART analysis.

\section{Methods}

\section{Study area}

This study was conducted in Wuxi, which is a modernized city located in Southeast Jiangsu Province, with geographical coordinates between 31.70 to $32.00 \mathrm{~N}$ and 119.31 to 120.36 E. In 2015, Wuxi had a total area of $4628 \mathrm{~km}^{2}$ and a resident population of 6.5 million, and the urban population accounted for $51.7 \%$ of the total population. People aged $0-14,15-64$, and $\geq 65$ years accounted for $10.4,78.2$, and $11.4 \%$ of the total population, respectively. The average annual temperature was $16.8^{\circ} \mathrm{C}$ and ranged from -5.3 to $38.5^{\circ} \mathrm{C}$. The male/female sex ratio was 0.98 . The GDP of Wuxi was 850 billion RMB (125 billion US dollars) in 2015. All the information above was derived from the Statistical Yearbook of Wuxi in 2015 [30].

\section{Sample size and sampling design}

The sample size was calculated according to the formula provided by Lwanga and Lemeshow [31], assuming that the prevalence of IFI was $32 \%$, as reported among adults in four Chinese cities [13]. According to the OpenEpi calculation procedure (OpenEpi, Version 3.01, Atlanta, USA), with confidence level set at $95 \%$, power set at 80 , $5 \%$ for confidence limits, and 1.7 for design effect, the sample size required was 569. Taking no response into account, the number of adults for the study was estimated as 600 .

In our study, a multiple-stage random sampling method was used to select the study population of the urban area. In general, urban areas of cities in China have three classes of administrative divisions: district, subdistrict, and community. There were seven districts, 41 subdistricts and 442 communities in the urban area of Wuxi in 2015. First, three districts were randomly selected from all seven districts. Then, one subdistrict was randomly selected from each selected district. Finally, one community was randomly selected from each selected subdistrict, and 200 adults from each community were randomly selected. Therefore, a total of 600 adults from three communities that were representative of the urban population of Wuxi were recruited for the study. Details of the sampling method are presented in Fig. 1.

The inclusion criteria: healthy subjects aged $\geq 18$ years old were included.

The exclusion criteria: subjects were excluded if they were diagnosed with kidney, liver, heart, or endocrine diseases that may influence fluid consumption.

\section{Data collection}

Before the beginning of the household survey, all participants were informed of the aims and procedures of the survey, and those who signed their informed consent were recruited. Then, each participant was instructed to 


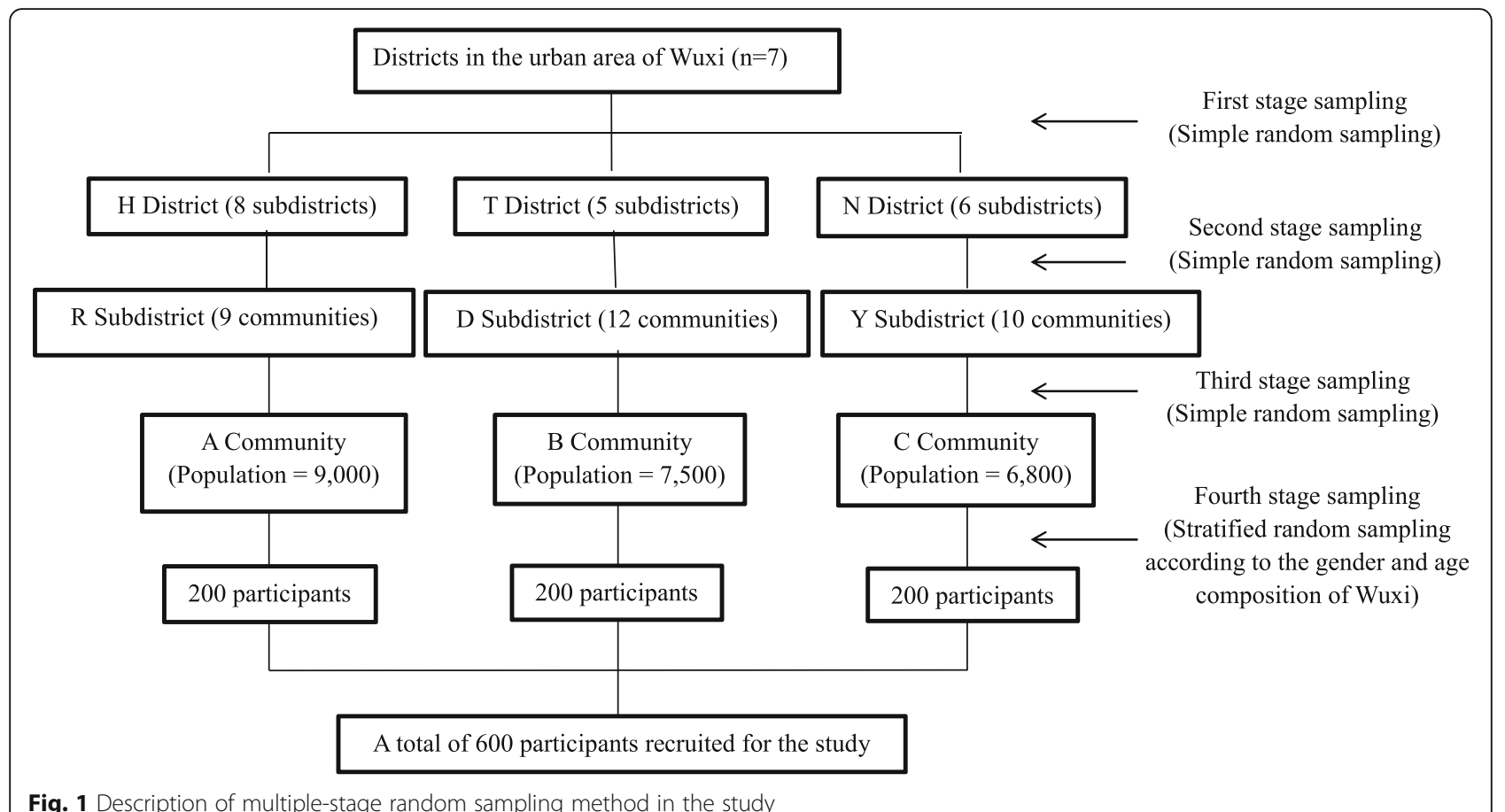

Fig. 1 Description of multiple-stage random sampling method in the study

complete a 24-h self-reported fluid intake diary. The participants recorded the types and amounts of fluid consumed over seven consecutive days (starting on the day of the survey). A graduated container $(100 \mathrm{~mL})$ was provided to each participant for accurate measurement of their fluid consumption. In addition, the demographic information of the participants, including age, gender, residential address, ethnicity, occupation, height, and weight, were collected by the investigators. Details about the fluid intake questionnaire are presented in Additional file 1.

We performed two rounds of the survey on the same participants in summer (August) and winter (December) in 2015. Outdoor temperature and humidity data of the study site for the seven-day study period were collected from the Meteorological Bureau of Wuxi. To increase the response rate, we chose the weekend as the first day of the household survey.

\section{Variables}

In our study, the volume of fluid intake was the sum of the following two sources: (a) plain water, including tap water, mineral water, purified water and tea water and (b) beverages, including tea drinks, carbonated drinks, fruit and vegetable drinks, plant protein drinks, energy drinks, solid drinks, plant drinks, milk drinks, coffee, milk and yogurt.

The CNS recommended a daily adequate intake of 1.5-1.7 L among adults who perform light physical activity under a moderate environmental temperature in
2016. Therefore, a daily fluid intake of less than $1.5 \mathrm{~L}$ was defined as IFI in our study.

Height in meters $(\mathrm{m})$ and weight in kilograms $(\mathrm{kg})$ were measured following a standardized procedure with steel tapes (DL3796, Deli, Zhejiang, China) and portable scales (EB9005L, Xiangshan, Guangdong, China) by investigators. Height and weight were measured twice (once in the summer and once in the winter), and average height and weight for each participant were calculated. The BMI was calculated as weight/height squared $\left(\mathrm{kg} / \mathrm{m}^{2}\right)$ and classified into four levels: $<18.5 \mathrm{~kg} / \mathrm{m}^{2}$ (underweight), $18.5-23.9 \mathrm{~kg} / \mathrm{m}^{2}$ (normal weight), $24-$ $27.9 \mathrm{~kg} / \mathrm{m}^{2}$ (overweight), and $\geq 28 \mathrm{~kg} / \mathrm{m}^{2}$ (obesity) [32].

The participants who were mainly engaged in physical activity (blue collar) were classified as labor workers, and the rest were classified as nonlabor workers.

\section{Statistical analysis}

The amount of fluid intake was presented as the median with 25th and 75th percentiles (P25-P75). Comparisons of the amount of fluid intake by demographic information, such as season, age, gender, location, ethnicity, occupation, BMI were performed with nonparametric test.

To identify the potential risk factors related to IFI (i.e., having IFI or not), the demographic variables were considered individually as independent variables included in Pearson's chi-square test. Then, multivariate analysis was applied to confirm the risk factors by logistic regression analysis (Enter), and the results were presented as adjusted odds ratio (OR) with $95 \%$ confidence interval 
(CI). Factors with $p<0.1$ in Pearson's chi-square test were selected as the independent variables in the logistic regression.

CART is a machine-learning algorithm that portions the data into subsets by threshold. A CART analysis model was applied to further explore the association between IFI and demographic variables. The analysis was performed for men and women in different seasons.

Descriptive analysis, nonparametric test, Pearson's chisquare test, and multivariate analysis were performed using SPSS software (version 20.0; IBM SPSS Institute, Inc., Armonk, NY, USA). Regression tree analysis was performed using $\mathrm{R}$ software (version 3.4.0, Package: rpart). Statistical significance was set at $p<0.05$. All data were checked for completeness and accuracy before analyses. Incomplete or no-response diaries were excluded from the final analyses.

\section{Results}

\section{Characteristics of the participants}

In total, $2.7 \%(16 / 600)$ of the participants were excluded, and 584 adults aged $18-87$ years from three communities $(\mathrm{A}, \mathrm{B}$, and $\mathrm{C}$ ) were included in the study. The participants were categorized into three age groups: $18-34$ years $(n=195,33.4 \%), 35-54$ years $(n=191,32.7 \%)$, and $\geq 55$ years $(n=198,33.9 \%)$. The average age of the participants was $45.0 \pm 16.9$ years.

Among the participants, 278 (47.6\%) were men and $306(52.4 \%)$ were women, with a male/female sex ratio of 0.908 . The majority of the participants were Han Chinese $(n=579,99.1 \%)$ and claimed to be nonlabor workers $(n=482,82.5 \%)$. In addition, individuals classified as $B M I<18.5 \mathrm{~kg} / \mathrm{m}^{2}$ and $B M I \geq 28 \mathrm{~kg} / \mathrm{m}^{2}$ accounted for $4.8 \%(n=28)$ and $4.3 \%(n=25)$, respectively. The general characteristics of the participants in the study are described in Table 1.

\section{Temperature and humidity}

The mean values of outdoor temperature and humidity for the seven days were $28.3^{\circ} \mathrm{C}$ and $74.4 \%$ in summer and $5.9{ }^{\circ} \mathrm{C}$ and $78.6 \%$ in winter. Details of the outdoor temperature and humidity of the seven days are presented in Additional file 2.

\section{Daily fluid intake of the participants}

The median (P25-P75) daily fluid intake of the participants was 1050 (750-1400) mL. Regarding the different seasons, the median (P25-P75) daily fluid intake of the participants was $1000(750-1300) \mathrm{mL}$ in winter, which was significantly lower than that in summer $(1100(800-$ 1550) $\mathrm{mL}, p<0.0001)$. For men, the daily fluid intake was significantly higher in summer than in winter $(1300$ vs $1100 \mathrm{~mL} /$ day, $p<0.0001)$. However, no significant
Table 1 Characteristics of the participants in the study

\begin{tabular}{|c|c|c|}
\hline Variables & No. of Participants & Percent \\
\hline Total & 584 & 100 \\
\hline \multicolumn{3}{|l|}{ Gender } \\
\hline Man & 278 & 47.6 \\
\hline Woman & 306 & 52.4 \\
\hline \multicolumn{3}{|l|}{ Age (years) } \\
\hline $18-34$ & 195 & 33.4 \\
\hline $35-54$ & 191 & 32.7 \\
\hline$\geq 55$ & 198 & 33.9 \\
\hline \multicolumn{3}{|c|}{ Location (Community) } \\
\hline A & 193 & 33.0 \\
\hline B & 192 & 32.9 \\
\hline C & 199 & 34.1 \\
\hline \multicolumn{3}{|l|}{ Ethnicity } \\
\hline Han & 579 & 99.1 \\
\hline Others & 5 & 0.9 \\
\hline \multicolumn{3}{|c|}{ Labor worker } \\
\hline Yes & 102 & 17.5 \\
\hline No & 482 & 82.5 \\
\hline \multicolumn{3}{|l|}{$\mathrm{BMI}\left(\mathrm{kg} / \mathrm{m}^{2}\right)$} \\
\hline$<18.5$ & 28 & 4.8 \\
\hline $18.5-23.9$ & 368 & 63.0 \\
\hline $24-27.9$ & 163 & 27.9 \\
\hline$\geq 28$ & 25 & 4.3 \\
\hline
\end{tabular}

difference was found for women between summer and winter.

Women were more likely to consume less fluids than men in both summer (1000 vs $1300 \mathrm{~mL} /$ day, $p<0.0001)$ and winter (996 vs $1100 \mathrm{~mL} /$ day, $p<0.0001)$. Individuals with $\mathrm{BMI}<18.5 \mathrm{~kg} / \mathrm{m}^{2}$ were more likely to consume less fluids than individuals with BMI $24-27.9 \mathrm{~kg} / \mathrm{m}^{2}$ in summer ( 800 vs $1300 \mathrm{~mL} /$ day, $p=0.041)$. A significant difference in fluid consumption was observed in different communities in winter $(p=0.002)$ : individuals living in $\mathrm{A}$ and $\mathrm{B}$ Community had a lower consumption of fluids than those in C Community (1000 vs $1100 \mathrm{~mL} /$ day, $p=$ $0.029 ; 950 \mathrm{~mL}$ vs $1100 \mathrm{~mL} /$ day, $p=0.002$ ). However, there was no significant difference among the communities in summer. The daily fluid intake of certain adults in summer and winter is shown in Table 2.

\section{Prevalence and risk factors associated with IFI using multivariate logistic regression}

In total, 898 out of 1168 (76.9\%) participants had IFI. In winter, the prevalence of IFI was $82.5 \%$, which was significantly higher than that in summer (71.2\%) (OR = 1.908, 95\% CI: 1.444-2.522). For men, the prevalence of IFI was significantly higher in winter than in summer 
Table 2 Description of daily fluid intake $(\mathrm{mL})$ among adults (18-87 years) in summer and winter $(n=584)$

\begin{tabular}{|c|c|c|c|c|c|}
\hline \multirow[t]{2}{*}{ Variables } & \multirow[t]{2}{*}{$\mathrm{N}$} & \multicolumn{2}{|l|}{ Summer } & \multicolumn{2}{|l|}{ Winter } \\
\hline & & Median (P25-P75) & $p$ & Median(P25-P75) & $p$ \\
\hline \multicolumn{6}{|l|}{ Gender } \\
\hline Man & 278 & 1300 (900-1750) & \multirow[t]{2}{*}{$<0.0001$} & $1100(800-1450)$ & \multirow[t]{2}{*}{$<0.0001$} \\
\hline Woman & 306 & 1000 (700-1350) & & $996(700-1250)$ & \\
\hline \multicolumn{6}{|l|}{ Age (years) } \\
\hline $18-34$ & 195 & 1050 (700-1550) & \multirow[t]{3}{*}{0.062} & $950(700-1250)$ & \multirow[t]{3}{*}{0.128} \\
\hline $35-54$ & 191 & $1200(800-1500)$ & & $1000(800-1400)$ & \\
\hline$\geq 55$ & 198 & 1200 (819-1550) & & $1025(800-1300)$ & \\
\hline \multicolumn{6}{|c|}{ Location (Community) } \\
\hline A & 193 & $1220(850-1600)$ & \multirow[t]{3}{*}{0.206} & $1000(750-1300)^{*}$ & \multirow[t]{3}{*}{0.002} \\
\hline B & 192 & $1100(758-1600)$ & & $950(650-1250)^{* *}$ & \\
\hline C & 199 & $1100(700-1430)$ & & $1100(900-1300)$ & \\
\hline \multicolumn{6}{|l|}{ Labor worker } \\
\hline Yes & 102 & $1100(650-1450)$ & \multirow[t]{2}{*}{0.094} & $923(650-1200)$ & \multirow[t]{2}{*}{0.025} \\
\hline No & 482 & $1110(800-1550)$ & & $1000(750-1300)$ & \\
\hline \multicolumn{6}{|l|}{$\mathrm{BMI}\left(\mathrm{kg} / \mathrm{m}^{2}\right)$} \\
\hline$<18.5$ & 28 & $800(475-1339)^{* * *}$ & \multirow[t]{4}{*}{0.012} & $900(613-1338)$ & \multirow[t]{4}{*}{0.374} \\
\hline $18.5-23.9$ & 368 & $1100(750-1500)$ & & $1000(750-1300)$ & \\
\hline $24-27.9$ & 163 & $1300(850-1650)$ & & $1000(750-1250)$ & \\
\hline$\geq 28$ & 25 & $1200(926-1650)$ & & $900(700-1150)$ & \\
\hline
\end{tabular}

*: $p=0.029$, compared with C Community; ${ }^{* *}: p=0.002$, compared with C Community; ${ }^{* * *}: p=0.041$, compared with BMI 24-27.9 kg/m²

Table 3 Multivariate analysis of risk factors associated with IFI among adults (18-87 years) in summer and winter $(n=584)$

\begin{tabular}{|c|c|c|c|c|c|c|c|}
\hline \multirow[t]{2}{*}{ Variables } & \multirow[b]{2}{*}{$\mathrm{N}$} & \multicolumn{3}{|l|}{ Summer } & \multicolumn{3}{|l|}{ Winter } \\
\hline & & No. (\%) & $\mathrm{aOR}(95 \% \mathrm{Cl})$ & $p$ & No. (\%) & $\mathrm{aOR}(95 \% \mathrm{Cl})$ & $p$ \\
\hline \multicolumn{8}{|l|}{ Gender } \\
\hline Woman & 306 & $248(81.0)$ & $2.683(1.830-3.934)$ & $<0.001$ & $272(88.9)$ & $2.636(1.677-4.142)$ & $<0.001$ \\
\hline Man & 278 & $168(60.4)$ & & & $210(75.5)$ & & \\
\hline \multicolumn{8}{|l|}{ Age } \\
\hline $18-34$ & 195 & $139(71.3)$ & & & $168(86.2)$ & 1 & 0.056 \\
\hline $35-54$ & 191 & $140(73.3)$ & & & $148(77.5)$ & $0.534(0.311-0.915)$ & 0.022 \\
\hline$\geq 55$ & 198 & $137(69.2)$ & & & $166(83.8)$ & $0.828(0.471-1.453)$ & 0.510 \\
\hline \multicolumn{8}{|c|}{ Location (Community) } \\
\hline A & 193 & $126(65.3)$ & 1 & 0.022 & 155 (80.3) & & \\
\hline B & 192 & $135(70.3)$ & $1.265(0.810-1.975)$ & 0.302 & $160(83.3)$ & & \\
\hline C & 199 & 155 (77.9) & $1.921(1.208-3.056)$ & 0.006 & 167 (83.9) & & \\
\hline \multicolumn{8}{|l|}{ Labor worker } \\
\hline Yes & 102 & 79 (77.5) & & & $88(86.3)$ & & \\
\hline No & 482 & $337(69.9)$ & & & $394(81.7)$ & & \\
\hline \multicolumn{8}{|l|}{ BMI $\left(\mathrm{kg} / \mathrm{m}^{2}\right)$} \\
\hline$<18.5$ & 28 & $22(78.6)$ & & & $25(89.3)$ & & \\
\hline $18.5-23.9$ & 368 & $275(74.7)$ & & & 301 (81.8) & & \\
\hline $24-27.9$ & 163 & $105(64.4)$ & & & $135(82.8)$ & & \\
\hline$\geq 28$ & 25 & $14(56.0)$ & & & $21(84.0)$ & & \\
\hline
\end{tabular}


$(75.5 \%$ vs $60.4 \%, \quad \mathrm{OR}=2.022,95 \%$ CI: $1.405-2.910)$. However, no significant difference was found for women between summer and winter.

The results of multivariate logistic regression suggested that women had a higher prevalence of IFI than men in both summer ( 81.0 vs $60.4 \%, O R=2.683$, 95\% CI: $1.830-3.934)$ and winter ( 88.9 vs $75.5 \%$, OR = 2.636, 95\% CI: 1.677-4.142). The prevalence of IFI among individuals aged 35-54 years was significantly lower than that among those aged 18-34 years in winter $(77.5$ vs $86.2 \%, \mathrm{OR}=0.534,95 \% \mathrm{CI}$ : $0.311-$ $0.915)$. In addition, significant differences in fluid intake were noted in different communities. Individuals who lived in $\mathrm{C}$ Community were more likely to have IFI than those who lived in A Community in summer (77.9 vs 65.3\%, OR $=1.921,95 \%$ CI: 1.208-3.056). However, the prevalence of IFI did not differ across occupations or BMI groups in either summer or winter. Table 3 presents the results of the multivariate analysis that identified the risk factors of IFI in summer and winter.

\section{Risk factors of IFI using CART analysis}

The risk factors contributing to IFI in summer according to CART analysis are delineated in Fig. 2. The prevalence of IFI in summer was $60.4 \%$ (168/278) for men and $81.0 \%(248 / 306)$ for women. For the first classified factor, men with $\mathrm{BMI}<25 \mathrm{~kg} / \mathrm{m}^{2}(64.2 \%, 136 / 212)$ were at greater risk of having IFI than those with $\mathrm{BMI} \geq 25$ $\mathrm{kg} / \mathrm{m}^{2}$ (48.5\%, 32/66). Moreover, for men with BMI $<25$ $\mathrm{kg} / \mathrm{m}^{2}$, the probability of IFI was higher among those aged $<64$ years $(67.4 \%, 122 / 181)$ than those aged $\geq 64$ years $(45.2 \%, 14 / 31)$ (Fig. 2a).

For women, BMI $<29 \mathrm{~kg} / \mathrm{m}^{2} \quad(81.6 \%, 244 / 299)$ was identified as the first risk factor for IFI in summer. In addition, individuals with $\mathrm{BMI}<29 \mathrm{~kg} / \mathrm{m}^{2}$ who lived in C Community $(86.7 \%, 91 / 105)$ were more likely to have IFI than those who lived in $\mathrm{A}$ and $\mathrm{B}$ Communities (78.9\%, 153/194). Furthermore, individuals with $\mathrm{BMI}<29 \mathrm{~kg} / \mathrm{m}^{2}$ in A and B Communities aged $<62$ years $(82.2 \%, 129 / 157)$ had a higher probability than those aged $\geq 62$ years $(64.9 \%, 24 / 37)$ (Fig. 2b).

The risk factors contributing to IFI in winter according to CART analysis are delineated in Fig. 3. The probability of IFI in winter was $75.5 \%(210 / 278)$ for men and $88.9 \%(272 / 306)$ for women. The figure shows that men aged $<40$ years $(81.8 \%, 90 / 110)$ had a higher probability of IFI than those aged $\geq 40$ years $(71.4 \%, 120 / 168)$ in winter. Furthermore, the probability of IFI was higher among men aged $\geq 46$ years $(76.6 \%, 105 / 137)$ than among those aged ranging from $\geq 40$ to $<46$ years $(48.4 \%, 15 / 31)$ (Fig. 3a).

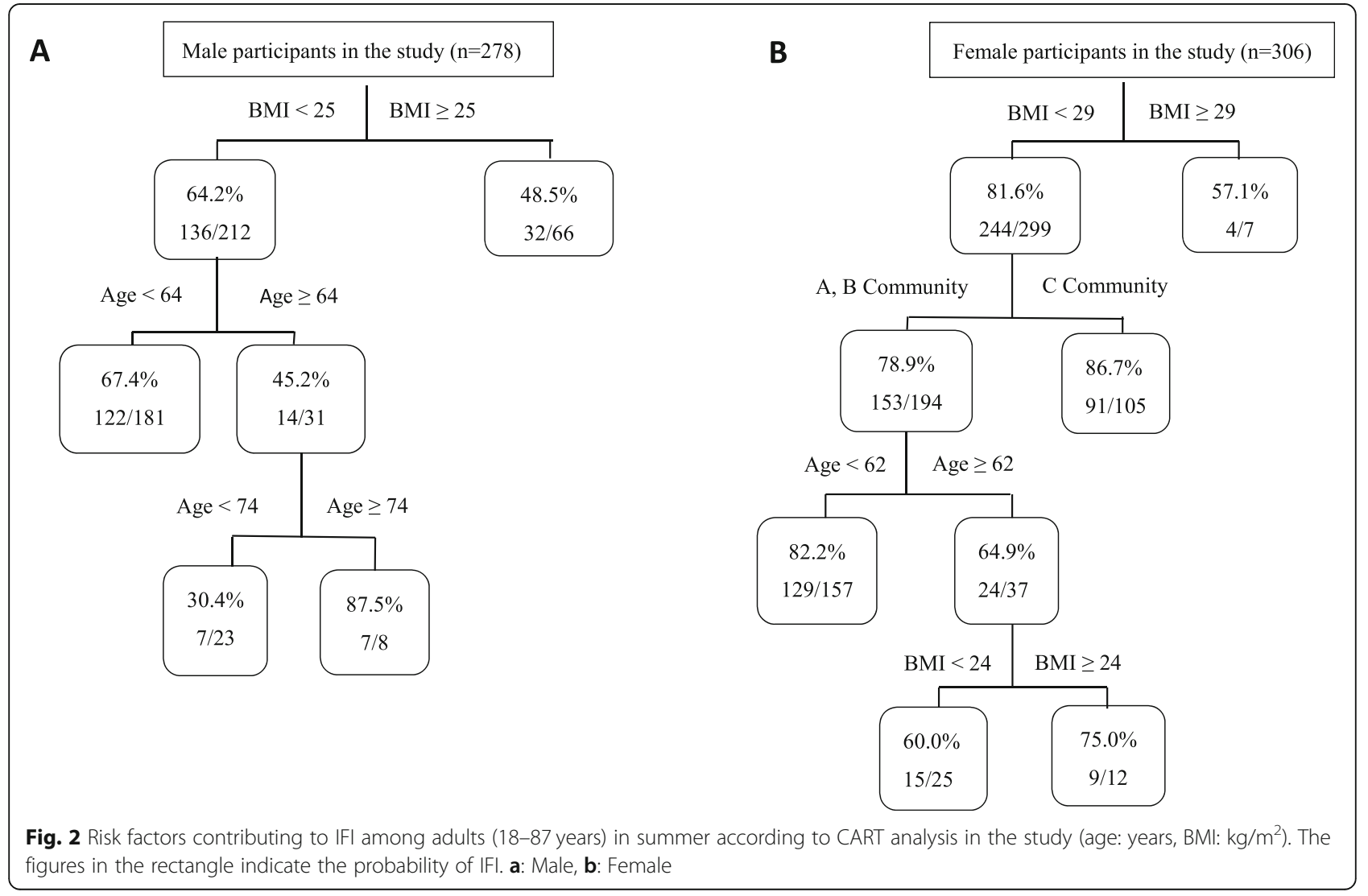




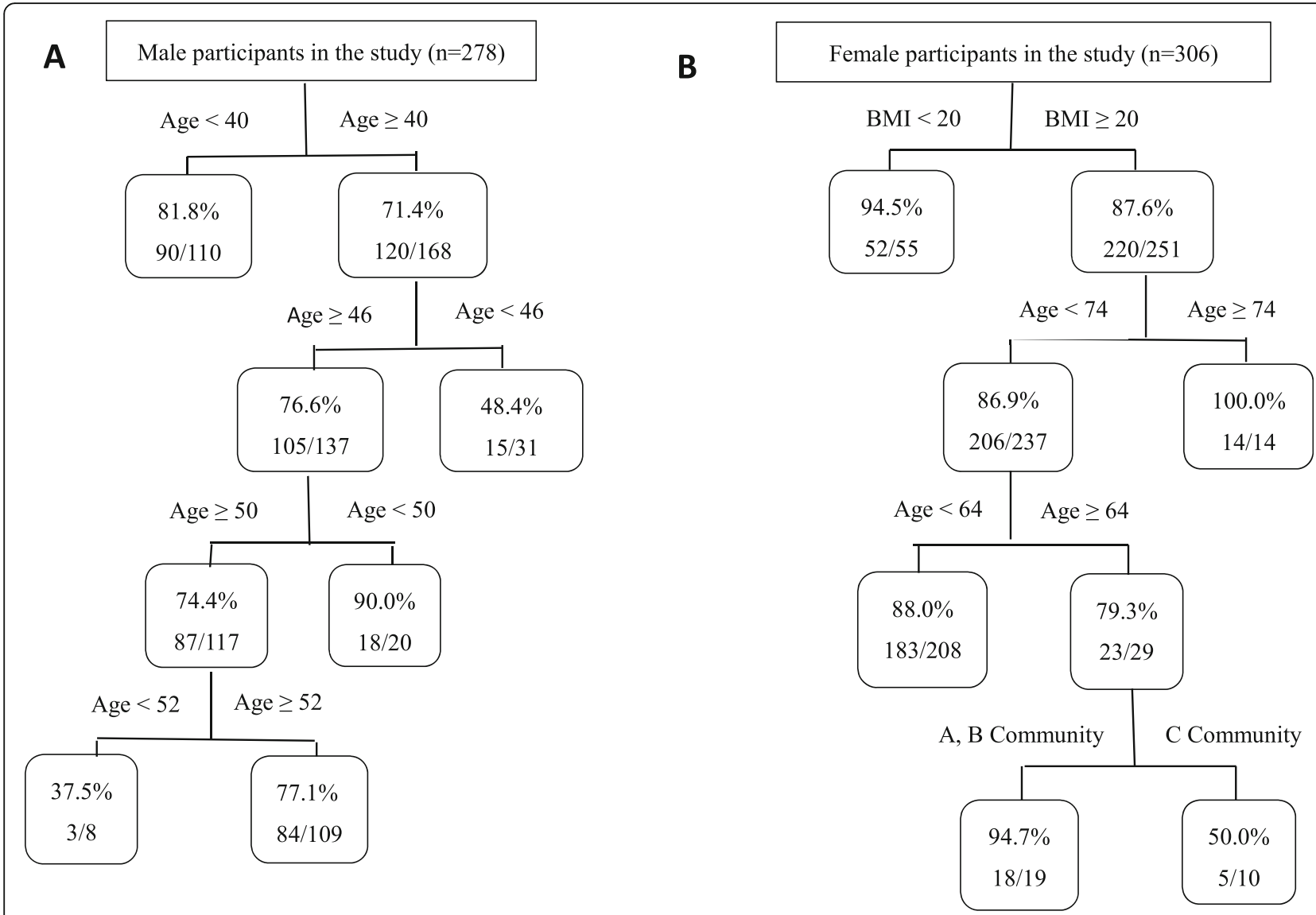

Fig. 3 Risk factors contributing to IFI among adults (18-87 years) in winter according to CART analysis in the study (age: years, BMl: $\mathrm{kg} / \mathrm{m}^{2}$ ). The figures in the rectangle indicate the probability of IFI. a: Male, b: Female

For women in winter, a BMI of $20 \mathrm{~kg} / \mathrm{m}^{2}$ was recognized as the first threshold, with individuals with $\mathrm{BMI}<20 \mathrm{~kg} / \mathrm{m}^{2}(94.5 \%, 52 / 55)$ having a higher probability of IFI than those with $\mathrm{BMI} \geq 20 \mathrm{~kg} / \mathrm{m}^{2}(87.6 \%, 220 / 251)$. Furthermore, for women with BMI $\geq 20 \mathrm{~kg} / \mathrm{m}^{2}$, the prevalence of IFI was higher among those aged $\geq 74$ years $(100.0 \%, 14 / 14)$ than among those aged $<74$ years $(86.9 \%$, 206/237). Additionally, for women with $\mathrm{BMI} \geq 20 \mathrm{~kg} / \mathrm{m}^{2}$ and aged $<74$ years, the probability of IFI was higher among those aged $<64$ years $(88.0 \%, 183 / 208)$ than among those aged $\geq 64$ years $(79.3 \%, 23 / 29)$ (Fig. 3b).

\section{Discussion}

This study assessed the fluid consumption among adults using a 24-h self-reported diary over seven consecutive days based on the urban population of Wuxi, China. Since plain water and beverages account for approximately $80 \%$ of the total water inputs, this study focused on the sum of plain water and beverages [10]. Our results suggested that most of the participants aged 18-87 years had IFI and the fluid consumption varied by gender, age, location, and BMI. In winter, the age of $<40$ years (probability: $81.8 \%$ ) and $\mathrm{BMI}<20 \mathrm{~kg} / \mathrm{m}^{2}$ (probability: 94.5\%) were identified as main risk factors contributing to IFI for men and women, respectively. Moreover, both the high-order interactive effects and thresholds of risk factors related to IFI have been detected in our study.

The results showed that the median daily fluid intake was $1050 \mathrm{~mL}$, which was lower than the findings of a survey of adults aged 18-55 years in 27 Chinese cities $(1214 \mathrm{~mL})[14]$ and a survey among young adults aged $18-23$ years in Baoding, China $(1135 \mathrm{~mL})$ [33]. These differences may be due to the different climate conditions and characteristics of the study populations. In addition, residents of Wuxi tended to eat porridge in the morning and evening, and the water intake from the porridge may have compensated for a portion of the total water intake. Ma et al. reported that the median daily fluid intake among 1483 adults aged 18-60 years in China was $1488 \mathrm{~mL}$, which is higher than the findings of our study [13]. However, the Ma et al. study was performed in Beijing, Shanghai, Chengdu, and Guangzhou. These four cities have a higher socioeconomic status than Wuxi, which may potentially increase the fluid intake of the participants [34]. The results also showed 
that most adults (76.9\%) failed to meet the recommended adequate intake guidelines set by CNS, a finding similar to that of the survey performed by Zhang $\mathrm{N}$ et al. (72\%) [14].

Our results also indicated that women consumed significantly less fluids than men in both summer and winter. Men generally have a higher metabolic rate than women at the same age due to the physiological disparity, and hence, the fluid requirements for men are higher than those for women. Several studies in China have reported that males had a higher fluid consumption than females among primary, middle school students [16-18], college students [23, 33], and adults [13, 14]. Our result is in accordance with these findings of China. Surveys performed in Ireland and the United Kingdom also reported that male adults consumed more fluids than females [35, 36]. However, studies conducted in Mexico and Spain reported that female adults had more fluid consumption than males [37, 38]. The differences may be due to the different drinking habits and age groups of the study population. Several studies have reported that the fluid intake of Chinese was affected by season [2325]. However, our study found that men had a higher prevalence of IFI in winter than in summer, which is different from the fluid intake of women. This result suggests that the fluid intake of men is more prone to be affected by season than women.

The results of CART analysis suggested that age $<40$ years was the first risk factor for men in winter. Multivariate analysis also indicated that the prevalence of IFI was significantly higher among those aged 18-34 years than among those aged $35-55$ years. We speculated that men aged $<40$ years are usually engaged in high-level activity and therefore may require more fluids. Additionally, young adults tend to ignore rehydration. Therefore, male adults aged $<40$ years were considered as a vulnerable group to IFI in winter. The difference in fluid intakes across different age groups was also reported in other studies [26, 28, 39].

The results of CART analysis suggested that $\mathrm{BMI}<25$ $\mathrm{kg} / \mathrm{m}^{2}$ and age $<64$ years were the first and second risk factors of IFI for men in summer, respectively, and $\mathrm{BMI}<20 \mathrm{~kg} / \mathrm{m}^{2}$ was the first risk factor for women in winter. We observed that the individuals with $\mathrm{BMI}<$ $18.5 \mathrm{~kg} / \mathrm{m}^{2}$ had a higher prevalence of IFI than individuals in other BMI groups in both summer and winter, although no statistical difference was found in the present study. Individuals with low BMI might have a lower level of water loss than those with high BMI. However, due to the limitation of the cross-sectional study design, no causal relations between low BMI and IFI in the study can be determined. A survey conducted among Irish adults indicated an association between lower fluid intake and higher BMI [35]. Instead, Kant et al. found an association between higher body mass and higher water intake in the adult US population [40]. Furthermore, data also suggested that age $<64$ years was associated with IFI for men in our study. Since the age of retirement for men is between 60 and 65 years in China, the retired population may have more spare time to pay attention to maintaining a healthy body hydration status. In contrast, S.M. Roche et al observed that men at an older age had lower water consumption in Canadian communities [26]. This association was also reported by other studies [41-44].

The volume of fluid intake varies across countries around the world. A systematic review was conducted to assess fluid intake from 2000 to 2013 and reported that the daily fluid intake among adults was $0.8-3.4 \mathrm{~L}$ worldwide [39]. Another survey conducted in 15 countries also showed considerable variation in fluid intake across countries [45]. In our study, the volume of fluid intake varied significantly across different communities. The CART analysis showed that, in summer, participants who lived in C Community had IFI, especially women with $\mathrm{BMI}<29 \mathrm{~kg} / \mathrm{m}^{2}$. Conversely, we also found that the volume of fluid intake in C Community was significantly higher than that in $\mathrm{A}$ and $\mathrm{B}$ Communities in winter. One possible reason is that the activity patterns of individuals in C Community may differ in summer and winter. It is also noteworthy that $\mathrm{C}$ Community was a relatively older community with a lower socioeconomic status than A and B Communities [30]. Studies from the United States and the United Kingdom reported that lower-income adults may be at greater risk of inadequate hydration than higher-income adults [34, 43, 46]. Zhang et al. also found that low socioeconomic status may decrease fluid consumption [14].

To the best of our knowledge, this is the first crosssectional study using CART analysis to determine the high-order interactions and thresholds of risk factors associated with IFI. Furthermore, risk factors were ranked according to their importance to IFI. The detection of risk factors can be useful for the identification of individuals who may at greater risk of dehydration. The sevenday self-reported method for assessing fluid intake has been validated for accuracy and reliability $[47,48]$, and this method has been widely used in previous studies $[13,14,33,45]$.

Limitations should be mentioned for our study. First, several factors that may potentially affect the fluid intake, such as season (spring and autumn), physical activity levels, income, and educational levels of the participants, were not considered. Second, according to the daily adequate fluid intake $(1.5-1.7 \mathrm{~L})$ recommended by CNS, $1.5 \mathrm{~L}$ was used as the threshold of IFI for general population in the present study. Detailed analysis using gender/age differentiated threshold of IFI should 
be employed in the further study. Finally, our study was conducted among the urban population in Wuxi, so the results may not be generalizable to the whole population. More extensive and large-scale investigations are required in the future.

\section{Conclusions}

Most of the participants living in the study site had IFI. The fluid consumption varied by gender, age, location, and BMI. The findings could be useful for the implementation and optimization of intervention programs by identifying the individuals who may at greater risk of dehydration.

\section{Supplementary information}

Supplementary information accompanies this paper at https://doi.org/10. 1186/s12889-020-8380-y.

Additional file 1: Details of the fluid intake questionnaire in the study.

Additional file 2: The temperature and humidity of seven days.

\section{Abbreviations}

BMI: Body mass index; CART: Classification and regression tree;

Cl: Confidence interval; CNS: Chinese nutrition society; IFI: Insufficient fluid intake; OR: Odds ratio

\section{Acknowledgements}

The authors are grateful for the contributions of the staffs of Wuxi Center for Disease Control and Prevention and Chinese Center for Disease Control and Prevention.

\section{Authors' contributions}

WBH and ZD conceived the study and modified the manuscript. HZ, JF, WJZ performed the survey and collected the data. $\mathrm{HZ}$ and JF analyzed the research data. $\mathrm{HZ}$ was responsible for the literature review and wrote the manuscript. ZD, WBH, and LZ contributed to the interpretation of the results. All authors read and approved the final manuscript.

\section{Funding}

The study was supported by National Water Pollution Control and Management Foundation of China (2014ZX07405001), Key Talent Project for Medical Young Scholar of Jiangsu Province (QNRC2016551), and Foundation of Jiangsu Commission of Health (H2018094). The funders had no role in study design, data collection and analysis, decision to publish, or preparation of the manuscript.

\section{Availability of data and materials}

The datasets used during the current study are available from the corresponding authors on reasonable request.

\section{Ethics approval and consent to participate}

The study protocol and all the documents were approved by the Ethics Committee of National Institute of Environmental Health, Chinese Center for Disease Control and Prevention. All the subjects signed the consents before the household survey.

\section{Consent for publication}

Not applicable.

\section{Competing interests}

The authors declare that they have no competing interests.

\section{Author details}

${ }^{1}$ Department of Environmental Health, Jiangsu Provincial Center for Disease Control and Prevention, No. 172 Jiangsu Road, Nanjing 210009, China.
${ }^{2}$ National Institute of Environmental Health, Chinese Center for Disease Control and Prevention, No. 29 Nanwei Road, Beijing 100050, China. ${ }^{3}$ Department of Public Health, Wuxi Center for Disease Control and Prevention, No. 499 Jincheng Road, Wuxi 214023, China. ${ }^{4}$ School of Public Health and Social Work, Institute of Health and Biomedical Innovation, Queensland University of Technology, Brisbane, Queensland 4059, Australia.

Received: 19 December 2018 Accepted: 20 February 2020

Published online: 04 March 2020

\section{References}

1. Jequier E, Constant F. Water as an essential nutrient: the physiological basis of hydration. Eur J Clin Nutr. 2010;64(2):115-23.

2. Haussinger D. The role of cellular hydration in the regulation of cell function. Biochem J. 1996:313(Pt 3):697-710.

3. El-Sharkawy AM, Sahota O, Lobo DN. Acute and chronic effects of hydration status on health. Nutr Rev. 2015;73(Suppl 2):97-109.

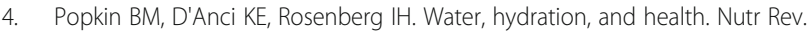
2010;68(8):439-58.

5. Ritz P, Berrut G. The importance of good hydration for day-to-day health. Nutr Rev. 2005;63(6 Pt 2):S6-13.

6. Armstrong LE. Challenges of linking chronic dehydration and fluid consumption to health outcomes. Nutr Rev. 2012;70(Suppl 2):S121-7.

7. Lieberman HR. Hydration and cognition: a critical review and recommendations for future research. J Am Coll Nutr. 2007;26(5 Suppl): 555S-61S.

8. Sawka MN, Cheuvront SN, Carter R 3rd. Human water needs. Nutr Rev. 2005; 63(6 Pt 2):S30-9.

9. Institute of Medicine. Dietary Reference Intakes for Water, Potassium, Sodium, Chloride, and Sulfate. Washington, DC: The National Academies Press; 2005.

10. EFSA. Scientific Opinion on Dietary Reference Values for water. EFSA J. 2010; 8(3):1459-506.

11. Laurent Le Bellego CJ, Jimenez L, Magnani C. Understanding fluid consumption patterns to improve healthy hydration. Nutrtion Today. 2010;45:22

12. Chinese Nutrition Society. Chinese Dietary Gudielines. Beijing: People's Medical Publishing House; 2016.

13. Ma G, Zhang Q, Liu A, Zuo J, Zhang W, Zou S, Li X, Lu L, Pan H, Hu X. Fluid intake of adults in four Chinese cities. Nutr Rev. 2012:70(Suppl 2):S105-10.

14. Zhang N, Morin C, Guelinckx I, Moreno LA, Kavouras SA, Gandy J, Martinez H, Salas-Salvado J, Ma G. Fluid intake in urban China: results of the 2016 Liq. In (7) national cross-sectional surveys. Eur J Nutr. 2018;57(Suppl 3):77-88.

15. Du S, Hu X, Zhang Q, Wang X, Liu A, Pan H, He S, Ma G. Total drinking water intake and sources of children and adolescent in one district of Shenzhen. Wei Sheng Yan Jiu. 2013;42(3):433-6.

16. Zhang Q, Hu XQ, Du SM, Pan H, Wang XJ, Zhang D, Zhu ZN, Luo Y, Ju Y, Ma GS. Drinking in different periods of a day of primary and middle school students in four cities of China. Zhonghua Yu Fang Yi Xue Za Zhi. 2013: 47(3):214-8.

17. Du SM, Pan H, Hu XQ, Zhang Q, Wang XJ, Lu LX, Zou SR, Fan JW, Li XH, Ma GS. Water intake of primary and middle school students in four cities of China. Zhonghua Yu Fang Yi Xue Za Zhi. 2013;47(3):210-3.

18. Du SM, Hu XQ, Zhang Q, Wang XJ, Pan H, Gao JM, Song J, Gao CL, He ZF, Ma GS. Daily intake of plain water and beverages of primary and middle school students in four cities of China. Zhonghua Yu Fang Yi Xue Za Zhi. 2013;47(3):202-5.

19. Zhang Q, Zuo J, Pan H, Wang X, Zou S, Li X, Lu L, Nie S, Hu X, Ma G. Drinking behaviors of adults at different time of day in four cities of China in summer. Wei Sheng Yan Jiu. 2013:42(2):263-8.

20. Wang XJ, Hu XQ, Du SM, Pan H, Zhang Q, Yan L, Wang ZY, Nie SP, Yang JB, $\mathrm{Ma}$ GS. The relationship between within-day drinking occasion and intake amount of water of primary and middle school students in four cities of China. Zhonghua Yu Fang Yi Xue Za Zhi. 2013;47(3):206-9.

21. Zhang N, Du S, Tang Z, Zheng M, Yan R, Zhu Y, Ma G. Hydration, fluid intake, and related urine biomarkers among male College Students in Cangzhou, China: a cross-sectional study-applications for assessing fluid intake and adequate water intake. Int J Environ Res Public Health. 2017; 14(5):513-24.

22. Wang Z, Shi A, Chen Y, Cheng W, Song J, Zhu Z, Zou S, Ma G. Water intake and its influencing factors of children and adolescents in Shanghai. Wei Sheng Yan Jiu. 2014;43(1):66-9. 
23. Zheng C, Yang Y. Influencing factors of the amount of drinking water by Changsha college students: a multilevel model analysis. Wei Sheng Yan Jiu. 2018;47(4):593-8

24. Xu P, Huang SB, Wang ZJ. Water consumption habit in general population of Shanghai and Beijing, China. Asican J Etotoxicol. 2008;3(3):224-30.

25. Zhao J, Wei J, Chen H, Liu Y, Li T, Sun Q, Liu Q. Multilevel model analysis on the relevant factors influencing the total amount of drinking water consumed daily by Beijing residents. Wei Sheng Yan Jiu. 2012;41(5):809-13.

26. Roche SM, Jones AQ, Majowicz SE, McEwen SA, Pintar KD. Drinking water consumption patterns in Canadian communities (2001-2007). J Water Health. 2012;10(1):69-86.

27. Jones AQ, Majowicz SE, Edge VL, Thomas MK, MacDougall L, Fyfe M, Atashband S, Kovacs SJ. Drinking water consumption patterns in British Columbia: an investigation of associations with demographic factors and acute gastrointestinal illness. Sci Total Environ. 2007:388(1-3):54-65.

28. Ferreira-Pego C, Guelinckx I, Moreno LA, Kavouras SA, Gandy J, Martinez H, Bardosono S, Abdollahi M, Nasseri E, Jarosz A, et al. Total fluid intake and its determinants: cross-sectional surveys among adults in 13 countries worldwide. Eur J Nutr. 2015:54(Suppl 2):35-43.

29. Lemon SC, Roy J, Clark MA, Friedmann PD, Rakowski W. Classification and regression tree analysis in public health: methodological review and comparison with logistic regression. Ann Behav Med. 2003;26(3):172-81.

30. Yang J. Wuxi Statistical Yearbook 2015. Beijing: China Statistical Press; 2015.

31. Lwanga SK, Lemeshow S. Sample size determination in health studies: a practical manual. Geneva: World Health Organization; 1991.

32. Wu Y. Overweight and obesity in China. BMJ. 2006;333(7564):362-3.

33. Zhang J, Zhang N, Liang S, Wang Y, Liu S, Liu S, Du S, He H, Xu Y, Cai H, et al. The amounts and contributions of total drinking fluids and water from food to total water intake of young adults in Baoding, China. Eur J Nutr. 2019:58(7):2669-77.

34. Brooks CJ, Gortmaker SL, Long MW, Cradock AL, Kenney EL. Racial/ethnic and socioeconomic disparities in hydration status among US adults and the role of tap water and other beverage intake. Am J Public Health. 2017 107(9):1387-94.

35. O'Connor L, Walton J, Flynn A. Water intakes and dietary sources of a nationally representative sample of Irish adults. J Hum Nutr Dietetics. 2014 27(6):550-6.

36. Gandy J. First findings of the United Kingdom fluid intake study. Nutr Today. 2012;47:S14-6.

37. Martinez $\mathrm{H}$. Fluid intake in Mexican adults; a cross-sectional study. Nutr Hosp. 2014;29(5):1179-87.

38. Ferreira-Pego C, Babio N, Fenandez-Alvira JM, Iglesia I, Moreno LA, SalasSalvado J. Fluid intake from beverages in Spanish adults; cross-sectional study. Nutr Hosp. 2014;29(5):1171-8.

39. Ozen AE, Bibiloni Mdel M, Pons A, Tur JA. Fluid intake from beverages across age groups: a systematic review. J Hum Nutr Dietetics. 2015;28(5): 417-42.

40. Kant AK, Graubard BI, Atchison EA. Intakes of plain water, moisture in foods and beverages, and total water in the adult US population--nutritional, meal pattern, and body weight correlates: National Health and nutrition examination surveys 1999-2006. Am J Clin Nutr. 2009;90(3):655-63.

41. Phillips PA, Rolls BJ, Ledingham JG, Forsling ML, Morton JJ, Crowe MJ, Wollner $\mathrm{L}$. Reduced thirst after water deprivation in healthy elderly men. $\mathrm{N}$ Engl J Med. 1984;311(12):753-9.

42. Sawka MN. Physiological consequences of hypohydration: exercise performance and thermoregulation. Med Sci Sports Exerc. 1992;24(6):65770 .

43. Drewnowski A, Rehm CD, Constant F. Water and beverage consumption among adults in the United States: cross-sectional study using data from NHANES 2005-2010. BMC Public Health. 2013;13:1068.

44. Ji K, Kim Y, Choi K. Water intake rate among the general Korean population. Sci Total Environ. 2010:408(4):734-9.

45. Martinez H, Guelinckx I, Salas-Salvado J, Gandy J, Kavouras SA, Moreno LA. Harmonized Cross-Sectional Surveys Focused on Fluid Intake in Children, Adolescents and Adults: The Liq.In7 Initiative. Ann Nutr Metab. 2016;68 Suppl 2:12-8.

46. Vieux F, Maillot M, Constant F, Drewnowski A. Water and beverage consumption patterns among 4 to 13-year-old children in the United Kingdom. BMC Public Health. 2017;17(1):479.

47. Johnson EC, Peronnet F, Jansen LT, Capitan-Jimenez C, Adams JD, Guelinckx I, Jimenez L, Mauromoustakos A, Kavouras SA. Validation testing demonstrates efficacy of a 7-day fluid record to estimate daily water intake in adult men and women when compared with Total body water turnover measurement. J Nutr. 2017;147(10):2001-7.

48. Hernandez-Cordero S, Lopez-Olmedo N, Rodriguez-Ramirez S, BarqueraCervera S, Rivera-Dommarco J, Popkin B. Comparing a 7-day diary vs. 24 hrecall for estimating fluid consumption in overweight and obese Mexican women. BMC Public Health. 2015;15:1031.

\section{Publisher's Note}

Springer Nature remains neutral with regard to jurisdictional claims in published maps and institutional affiliations.
Ready to submit your research? Choose BMC and benefit from:

- fast, convenient online submission

- thorough peer review by experienced researchers in your field

- rapid publication on acceptance

- support for research data, including large and complex data types

- gold Open Access which fosters wider collaboration and increased citations

- maximum visibility for your research: over $100 \mathrm{M}$ website views per year

At $\mathrm{BMC}$, research is always in progress.

Learn more biomedcentral.com/submissions 